\title{
Development and pilot testing of novel game-based respiratory rehabilitation exercise devices for patients with tetraplegia
}

\author{
Jiyoung Park, Dongheon Kang ${ }^{1}$ and Seon-Deok Eun* \\ Ministry of Health and Welfare, National Rehabilitation Center, National Rehabilitation Research \\ Institute, Department of Healthcare and Public Health Research, Seoul, Korea
}

Received 25 January 2021

Accepted 8 May 2021

\begin{abstract}
.
BACKGROUND: Individuals with spinal cord injuries (SCI) show restricted breathing patterns with reduced lung volumes and capacities.

OBJECTIVE: To improve breathing in such individuals, we aimed to develop breathing exercise devices using a user-centered design (UCD) and then assess the effects of these devices on breathing.

METHODS: Patients with SCI were involved in the device development. Preliminary online survey participants were recruited from the community, and interview and pilot test participants were recruited from a patient self-help group. The four UCD phases were repeatedly performed. Users required fun, easy, multi-player, and safe exercise devices.

RESULTS: Seven breathing exercise devices were developed, and 10 different game-based exercises were performed. Two individuals participated in a pilot test involving a respiratory rehabilitation exercise program conducted twice weekly for $60 \mathrm{~min} / \mathrm{session}$ over 8 weeks. Lung function was assessed using a spirometer. Forced vital capacity, forced expiratory volume in $1 \mathrm{~s}$, and vital capacity showed minimal changes, whereas maximum inspiratory and expiratory pressures improved. Participants reported that the exercises were entertaining and that the competitive nature of the game-like exercises encouraged further participation.

CONCLUSION: Breathing exercise programs using our developed devices can improve breathing and positively affect the psychological states and sociability of users.
\end{abstract}

Keywords: Breathing exercise, disability, game-based exercise devices, health, patients, respiratory rehabilitation, spinal cord injuries, tetraplegia, user-centered design

\section{Introduction}

Pneumonia is the leading cause of death in patients with spinal cord injuries (SCI) [1] as SCI reduces the respiratory functions of inspiratory and expiratory muscles such as the diaphragm, intercostal muscles, auxiliary respiratory muscles, and abdominal muscles [2,3]. In patients with severe cervical SCI (CSCI),

\footnotetext{
${ }^{1}$ Dongheon Kang, as the co-first author.

${ }^{*}$ Corresponding author: Seon-Deok Eun, Ministry of Health and Welfare, National Rehabilitation Center, National Rehabilitation Research Institute, Department of Healthcare and Public Health Research, 58, Samgaksan-ro, Gangbuk-gu, Seoul, 01022, Korea. Tel.: +82 2901 1917; Fax: +82 2901 1930; E-mail: esd7786@korea.kr.
} 
decreased pulmonary function increases the risk of developing pneumonia and atelectasis, leading to respiratory complications and mortality [4]. Such respiratory complications are observed in $67 \%$ of patients with SCI [1] and are frequent causes of hospitalization. Most respiratory complications are caused by insufficient ventilation and impaired airway secretion removal and are observed in $40 \%$ and $23 \%$ of those with CSCI (C1-C4) and lower CSCI (C5-C8), respectively [5]. In patients with severe spinal injuries, such as CSCI, vital and functional residual capacities decrease by up to $50 \%$ and $75 \%$, respectively $[3,6]$. Decreased respiratory function causes sputum production and difficulties in breathing, negatively affecting the daily life of patients with CSCI [7].

Breathing exercises are essential for improving lung function and decreasing respiratory complications $[8,9]$. Appropriate breathing exercises for those with CSCI can significantly reduce respiratory complication frequency [10], consequently lowering the mortality rate, decreasing complication prevalence, and increasing the quality of life (QoL) [11]. Breathing exercises have been reported to be safe and effective for improving respiratory strength and coughing ability in patients with CSCI [12]. However, breathing exercises for such patients mainly involve respiratory trainers in hospitals and exercises that need to be performed repeatedly, such as singing, blowing candles and balloons, and playing with table tennis balls. Studies have reported that patients find these conventional methods tedious, and they are unlikely to improve breathing $[4,13]$.

In individuals with severe spine injuries who have limited body movement, breathing exercises need to be performed continuously to strengthen respiratory muscles and improve the residual strength of auxiliary respiratory muscles. However, most breathing exercise programs for patients with CSCI are hospital-based, and there is a lack of simple, effective, and fun breathing exercises. Therefore, we aimed to develop game-based breathing exercise devices using a user-centered design (UCD) for individuals with C3-C5 SCI. Additionally, we performed a pilot test to assess the effects of the breathing exercise program using these developed devices.

\section{Materials and methods}

\subsection{Ethics statements}

The study was conducted according to the guidelines of the Declaration of Helsinki and was approved by the Institutional Review Board of the Korea National Rehabilitation Center (NRC-2016-03-029). It was registered under the International Clinical Trials Registry (Development and Clinical Study of Rehabilitation Sports Program for Persons with Cervical Spinal Cord Injury; registration number, KCT0005780). Participants with CSCI were recruited from the Korea National Rehabilitation Center and the community. All participants agreed to participate in the study and signed a consent form prior to the start of the program.

\subsection{User-centered design}

In UCD, the process of understanding the user is repeated multiple times to reflect their specific requirements. We developed breathing exercise devices for patients with CSCI using UCD (Fig. 1).

\subsubsection{Specifying user requirements}

An online pilot survey was conducted on breathing exercises for patients with SCI recruited from the Korea National Rehabilitation Center and the community. In total, 14 individuals with C3-C5 injuries who acquired disabilities more than 5 years ago participated in the survey. Their responses to the online 


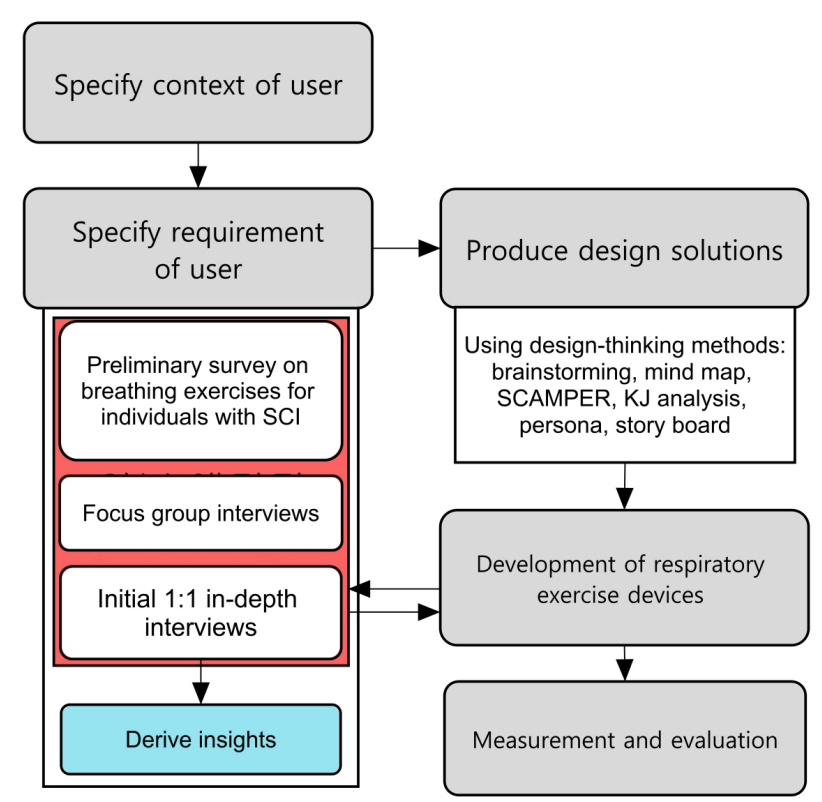

Fig. 1. User-centered design process for developing respiratory exercise devices.

Reasons for not performing exercises

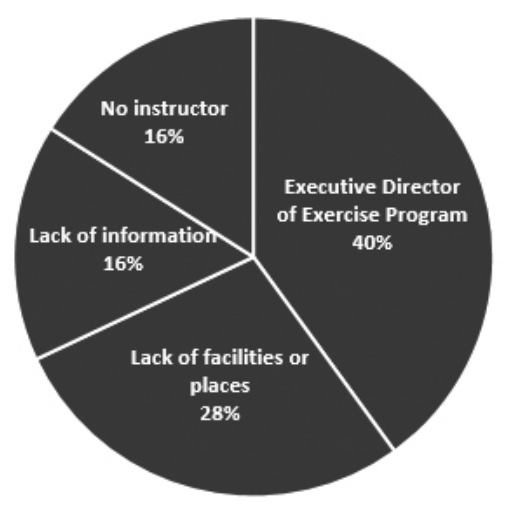

Body parts that require exercise

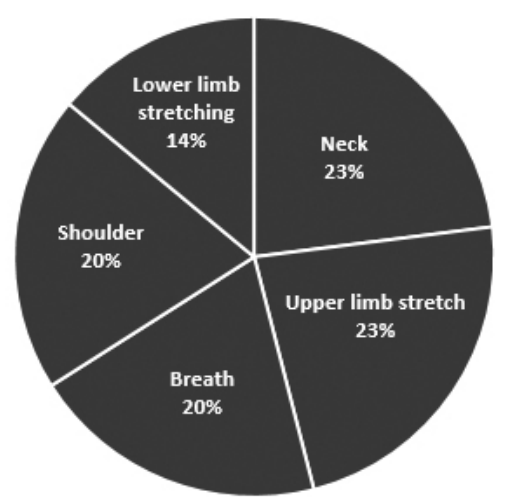

Fig. 2. Results of preliminary survey.

questionnaire are summarized in (Fig. 2). To assess the status, types, and difficulties of specific exercises in patients with severe CSCI, focus group interviews were conducted with 15 patients with severe CSI in the Korea National Rehabilitation Center self-help group. To assess specific user requirements, a one-on-one in-depth interview was conducted with five patients with severe CSCI.

The results of the preliminary survey, focus group interviews, and in-depth interviews indicated that patients with severe SCI require fun, multi-player, and competitive breathing exercises (Fig. 3). Thus, we concluded that our focus should be on game-based breathing exercises.

\subsubsection{Producing design solutions}

Ideas for game-based breathing exercise devices that met the requirements in Section 2.2.2 and that can improve breathing in patients with severe CSCI were sought using design-thinking methods, such 
Functional elements required in the devices

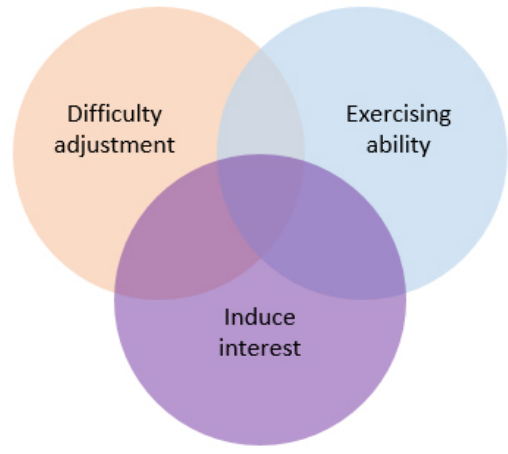

Fig. 3. Derived insights for developing breathing exercise devices.

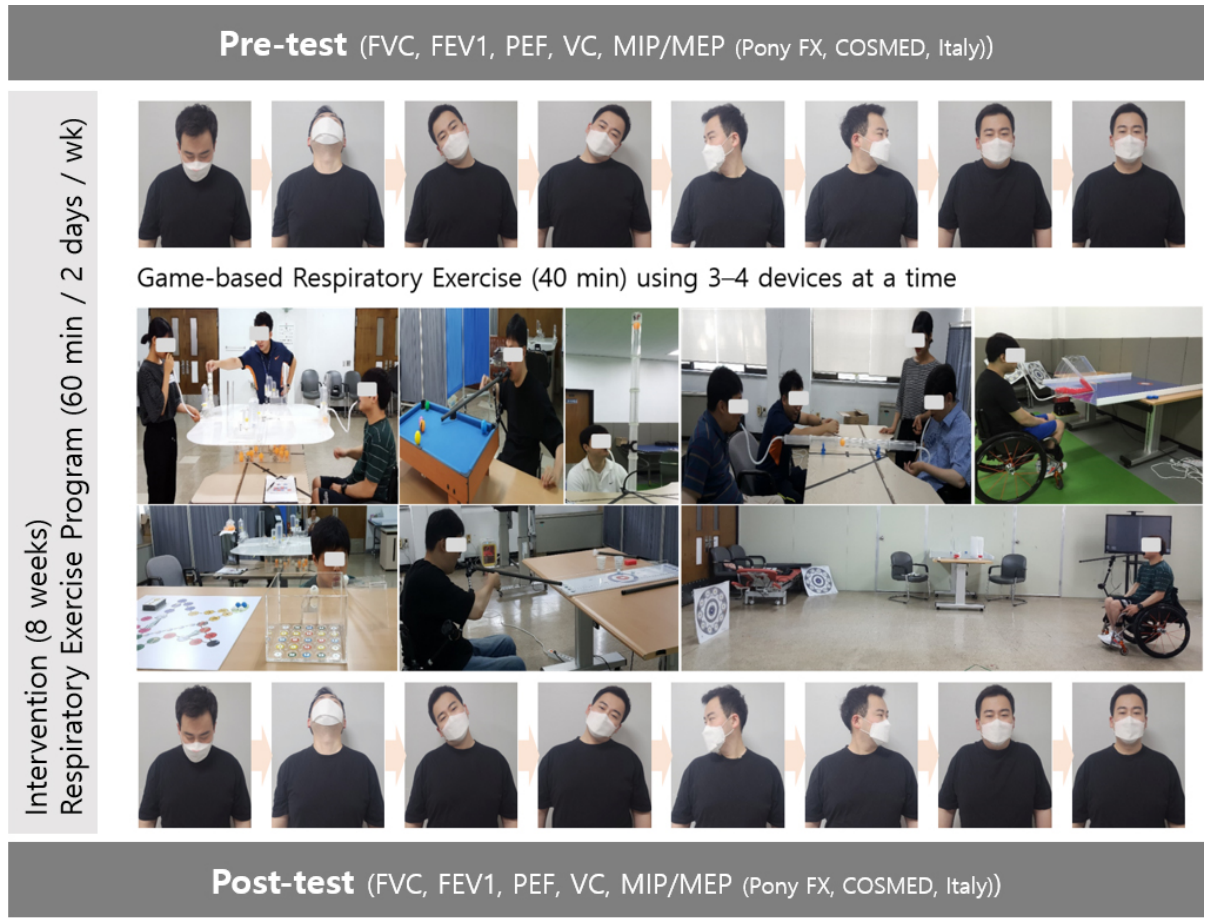

Fig. 4. Breathing exercises included in the developed breathing exercise devices. FEV1, forced expiratory volume in $1 \mathrm{~s} ; \mathrm{FVC}$, forced vital capacity; MEP, maximal expiratory pressure; MIP, maximal inspiratory pressure; PEF, peak expiratory flow; VC, vital capacity.

as brainstorming, mind maps, SCAMPER, KJ analysis, Persona, and storyboard (Fig. 4). Subsequently, these ideas were further detailed through repetitive work that reflected and corrected the suggestions of patients with severe CSCI. Moreover, a device manual was developed to ensure that the device could be used with or without assistance from others.

Breathing exercise devices (Table 1) were developed based on the requirements and ideas of patients with severe CSCI (Fig. 4). Details of the breathing exercise devices are presented in the Supplementary materials. 
Table 1

Breathing exercise device development*

\begin{tabular}{|c|c|c|}
\hline $\begin{array}{l}\text { Breathing exercise } \\
\text { devices }\end{array}$ & Explanation & Expected effect \\
\hline Breath goal-in & $\begin{array}{l}\text { An exercise where the participant needs to blow on a } \\
\text { mini-ball and score a goal by avoiding moving obstacles. } \\
\text { The game can be played alone or with up to four players. }\end{array}$ & $\begin{array}{l}\text { Inspiration (volume, strength, and peak) } \\
\text { and expiration (volume and peak) }\end{array}$ \\
\hline Breathing billiard & $\begin{array}{l}\text { A mini-pool table was created by reducing the area of } \\
\text { original-sized pool tables. The aim of this exercise was to } \\
\text { push balls of different weights by breathing. This game can } \\
\text { be performed alone or with up to four people. }\end{array}$ & $\begin{array}{l}\text { Inspiration (volume), expiration (peak), } \\
\text { and neck movement }\end{array}$ \\
\hline \multicolumn{3}{|l|}{ Multi-play ball } \\
\hline Lift ball competition & $\begin{array}{l}\text { The goal of this exercise was to lift the ball by breathing } \\
\text { into a cylinder. After the start signal, the distance from the } \\
\text { bottom of the cylinder to the bottom part of the ball was } \\
\text { measured using a ruler attached to the acrylic cylinder body. }\end{array}$ & $\begin{array}{l}\text { Inspiration (volume) and expiration } \\
\text { (volume, strength, and peak) }\end{array}$ \\
\hline $\begin{array}{l}\text { Ball reciprocating } \\
\text { count battle }\end{array}$ & $\begin{array}{l}\text { This exercise measured the number of times that the sound } \\
\text { sensor was touched by the ball for } 7 \mathrm{~s} \text { using a cylinder with } \\
\text { a sound sensor attached. }\end{array}$ & $\begin{array}{l}\text { Inspiration (volume and strength) and } \\
\text { expiration (volume, strength, and peak) }\end{array}$ \\
\hline Holding the ball & $\begin{array}{l}\text { This exercise measured the number of times that the sound } \\
\text { sensor was touched by the ball for } 7 \mathrm{~s} \text { using a cylinder with } \\
\text { a sound sensor attached. }\end{array}$ & $\begin{array}{l}\text { Inspiration (volume) and expiration } \\
\text { (volume and strength) }\end{array}$ \\
\hline Breathing tug-of-war & $\begin{array}{l}\text { A two-player exercise where players need to breathe and } \\
\text { move the ball towards their side for } 3 \mathrm{~s} \text {. }\end{array}$ & $\begin{array}{l}\text { Inspiration (volume, strength, and peak) } \\
\text { and expiration (volume, strength, and } \\
\text { peak) }\end{array}$ \\
\hline Breathing marble & $\begin{array}{l}\text { A board-game-like breathing exercise where missions need } \\
\text { to be completed. }\end{array}$ & $\begin{array}{l}\text { Inspiration (volume) and expiration } \\
\text { (volume and peak) }\end{array}$ \\
\hline Breathing curling & $\begin{array}{l}\text { A modified version of curling where the stone is blown } \\
\text { towards the target board. }\end{array}$ & $\begin{array}{l}\text { Inspiration (volume) and expiration } \\
\text { (volume, strength, and peak) }\end{array}$ \\
\hline Boroling & $\begin{array}{l}\text { A game that combines curling and bocci and is a sport for } \\
\text { those with severe disabilities. }\end{array}$ & $\begin{array}{l}\text { Inspiration (volume), expiration (volume } \\
\text { and strength), and neck movement }\end{array}$ \\
\hline Blowgun dart & $\begin{array}{l}\text { A game where blowgun bullets with suction plates are } \\
\text { blown using the blowgun to hit a target with a suction plate. }\end{array}$ & $\begin{array}{l}\text { Inspiration (volume), expiration (peak), } \\
\text { and neck movement }\end{array}$ \\
\hline
\end{tabular}

* Details of the exercise devices are presented in the Supplementary materials.

\subsection{Measurement and evaluation}

\subsubsection{Pilot test configuration}

The respiratory rehabilitation exercise program was performed twice a week for $60 \mathrm{~min} / \mathrm{session}$ over 8 weeks using breathing exercise devices. This one-time program consisted of warm-up exercises for $10 \mathrm{~min}$ to stretch muscles around the neck, game-based respiratory rehabilitation exercises for $40 \mathrm{~min}$, and cool-down exercises for $10 \mathrm{~min}$.

Two disabled individuals with C6 CSCI participated in the pilot test. The selection criteria were as follows: severely disabled individuals with complete motor nerve damage with an American Spinal Injury Association scale grade A or B; current non-smokers; absence of chronic or acute heart and respiratory diseases in the past or within the last 6 months; absence of comorbidities, such as rib cage deformity or rib fracture, before the accident that resulted in disability; absence of spinal arthritis or neuromuscular conditions that may affect lung function; agreement to participate in this study; and ability to understand instructions and cooperate.

\subsubsection{Assessment of respiratory function and user experience}

We evaluated changes in the respiratory function of participants before and after undergoing the breathing exercise program using the developed devices for 8 weeks. 
Table 2

General characteristics of disabled individuals with C6 cervical spinal cord injury who participated in this pilot study

\begin{tabular}{ccccccc}
\hline Participant number & Damaged level & ASIA scale & Sex & Duration since onset (months) & Height $(\mathrm{cm})$ & Weight $(\mathrm{kg})$ \\
\hline 1 & C6 & A & Male & 136 & 175 & 68 \\
2 & C6 & B & Male & 81 & 178 & 76 \\
\hline
\end{tabular}

ASIA, American Spinal Injury Association.

Table 3

Respiratory function assessment results

\begin{tabular}{lcccccccc}
\hline \multirow{2}{*}{ Variable } & \multicolumn{3}{c}{ Participant 1} & & \multicolumn{3}{c}{ Participant 2 } \\
\cline { 2 - 4 } \cline { 6 - 8 } & Before & After & Change & & Before & After & Change \\
\hline FVC (L) & 2.72 & 2.72 & 0 & & 2.97 & 3.15 & 0.18 \\
FEV1 (L) & 2.59 & 2.69 & 0.10 & & 2.11 & 2.19 & 0.08 \\
PEF (L/s) & 4.79 & 7.12 & 2.33 & & 5.88 & 7.56 & 1.68 \\
VC (L) & 2.03 & 2.87 & 0.84 & & 2.5 & 3.39 & 0.89 \\
MIP (cmH2O) & 28 & 94 & 66.00 & & 11 & 95 & 84 \\
MEP (cmH2O) & 37 & 62 & 25.00 & & 21 & 31 & 10 \\
\hline
\end{tabular}

FEV1, forced expiratory volume in $1 \mathrm{~s}$; FVC, forced vital capacity; MEP, maximal expiratory pressure; MIP, maximal inspiratory pressure; PEF, peak expiratory flow; VC, vital capacity.

Forced vital capacity (FVC), maximum air volume forcibly exhaled after maximum inhalation, 1-s forced expiratory volume (FEV1), and airway obstruction levels were measured. Other items measured included peak expiratory flow (PEF); vital capacity (VC), which is the maximum amount of air expelled after a maximum inhalation; and maximal inspiratory pressure and maximal expiratory pressure (MIP/MEP). Spirometry (Pony FX, COSMED, Rome, Italy) was used for measurement, and each variable was measured twice. Average values were used.

After completing the 8-week breathing exercise program, a one-on-one in-depth interview was conducted with each participant to evaluate their experience in the program, opinions on the developed device, mood during participation, changes after participation, and other factors.

\section{Results}

Participant characteristics are shown in Table 2.

Table 3 shows changes in individual lung function before and after the program, and all variables improved after the program. FVC, FEV1, and VC showed minimal changes, whereas MIP and MEP improved.

One-on-one in-depth interviews with the two participants of the pilot test indicated that the exercises were entertaining and motivated the participants to improve through competition. Moreover, the participants reported improvements in their breathing ability and QoL.

\section{Discussion}

In this study performed to develop improved breathing exercise devices, patients with tetraplegia requested improved breathing and entertaining exercises, and multi-player settings. Based on these requirements, game-based respiratory exercise devices were developed. Patients with tetraplegia participated directly in the development process. 
Tetraplegia caused by CSCI induces difficulties in moving the body, and there were no exercises that could be performed with existing devices to improve the condition of patients with tetraplegia. As no multi-player exercises existed, it was difficult to inspire competition, induce the desire to win, or motivate patients to perform exercises. Breathing exercises such as "air stacking training" and "spirometry training," which are conducted in hospitals or at home, are effective [14], but they are considered uninteresting, making it difficult for patients to consistently perform these exercises. The developed devices utilize the remaining function of the cervical spinal cord to achieve the exercise goal with or without a companion, consequently improving breathing ability.

The desired effects were confirmed by conducting a pilot 8-week breathing exercise program using the developed devices. The respiratory function of patients with severe SCI improved after completing the respiratory rehabilitation exercise program as indicated by the increased FVC, FEV1, PEF, VC, MIP, and MEP. These improvements were similar to those reported by Kim et al. [8], where FVC was significantly improved after 8 weeks of respiratory muscle training (RMT) in patients with SCI. Breathing exercises strengthened inhalation and exhalation muscles, thereby increasing FVC and FEV1. Therefore, the devices developed in this study could be used as tools for respiratory exercise interventions to effectively improve FVC.

Furthermore, PEF, VC, MIP, and MEP improved in our study, similar to the results reported by Mueller et al. [15], where PEF, VC, MIP, and MEP significantly improved after 8 weeks of RMT in patients with SCI. Changes in chest wall characteristics, such as recovered diaphragmatic function [16,17], increased auxiliary respiratory muscle performance [18], rib cage stability, and improved compliance may have led to such a result $[19,20]$. Moreover, this result suggests that hyperventilation during respiratory muscle exercises can strengthen the respiratory muscles of patients with CSCI.

We observed that performing game-based exercises with other people increased the interest of the participants and that the competitive nature of these exercises promoted positive psychological effects, such as voluntary participation and greater exercise engagement. Thus, these multi-player exercises may help reduce depression and improve the QoL of patients with severe SCI. However, the number of participants involved during device verification was small. To translate our program to a broader population, a larger sample size is required, and follow-up studies on the specifications and materials of devices should be conducted. Nonetheless, breathing exercises using our developed devices may motivate patients with tetraplegia to perform the breathing exercises.

The devices developed in this study can be used by everyone, including patients with CSCI; however, thorough disinfection and caution are required to prevent infectious respiratory diseases such as coronavirus disease 2019 and seasonal flu. Therefore, to achieve the widespread use of these devices, further improvements are required to ensure that they can be easily, conveniently, and safely disinfected and managed.

\section{Conclusions}

Patients with severe SCI requested game-based breathing exercises that they can perform with others. Study participants, the end-users of the developed products, directly contributed to the development of the exercise devices, and their requirements were fulfilled. After performing a respiratory rehabilitation program, the FEV, FEV1, VC, MIP, and MEP of the participants improved. Thus, our study demonstrated that the developed devices might improve respiratory function, as well as the psychological status and sociability of users owing to their game-like competitive design. Future research should assess the safety of the developed devices. 


\section{Acknowledgments}

The authors would like to thank all study participants, the staff, and the Korea National Rehabilitation Center, Ministry of Health \& Welfare in Seoul, Republic of Korea. This work was supported by the Korea National Rehabilitation Research Institute under Grant \#16-C-01.

\section{Author contributions}

Each author made significant individual contributions to this manuscript. JP (ORCID 0000-00020399-7083): literature review, writing, data interpretation, and critical review of the manuscript; DK (ORCID 0000-0001-8952-1547): literature review, breathing exercises intervention, data collection, data interpretation, and critical review of the manuscript; SDE (ORCID 0000-0001-8384-4484): supervision of the study, conception of the study, and critical review of the manuscript. All authors have read and agreed to the published version of the manuscript.

\section{Conflict of interest}

The authors declare no conflict of interest.

\section{Supplementary data}

The supplementary files are available to download from http://dx.doi.org/10.3233/THC-212860.

\section{References}

[1] Breath Easy Club. Respiratory rehabilitation for spinal cord injury patient [Internet]. 2007 [updated 2016 Feb 25; cited 2021 Jan 26]. Available from: http//www.breatheasyclub.com/.

[2] Linder SH. Functional electrical stimulation to enhance cough in quadriplegia. Chest. 1993; 103: 166-169. doi: 10.1378/ chest.103.1.166.

[3] McBain RA, Boswell-Ruys CL, Lee BB, Gandevia SC, Butler JE. Abdominal muscle training can enhance cough after spinal cord injury. Neurorehabil Neural Repair. 2013; 27: 834-843. doi: 10.1177/1545968313496324.

[4] Cochrane Database Syst Rev. 2031: 7: CD008507. doi: 10.1002/14651858.CD008507.pub2.

[5] Jackson AB, Groomes TE. Incidence of respiratory complications following spinal cord injury. Arch Phys Med Rehabil. 1994; 75: 270-275. doi: 10.1016/0003-9993(94)90027-2.

[6] Kim WH, Park HJ, Lee JE, Hong BJ. Effect of intermittent positive pressure breathing on pulmonary function in patients with cervical spinal cord injury. Korean J Neuromusc Rehabil. 2011; 1: 5-10.

[7] Van Houtte S, Vanlandewijck Y, Gosselink R. Respiratory muscle training in persons with spinal cord injury: a systematic review. Respir Med. 2006; 100: 1886-1895. doi: 10.1016/j.rmed.2006.02.029.

[8] Kim CY, Lee JS, Kim HD, Lee DJ. Short-term effects of respiratory muscle training combined with the abdominal drawing-in maneuver on the decreased pulmonary function of individuals with chronic spinal cord injury: a pilot randomized controlled trial. J Spinal Cord Med. 2017; 40: 17-25. doi: 10.1080/10790268.2016.1198576.

[9] Kirshblum S, Lin VW. Spinal Cord Medicine. 3rd ed. New York: Springer Publishing Company; 2018.

[10] Berlly M, Shem K. Respiratory management during the first five days after spinal cord injury. J Spinal Cord Med. 2007; 30: 309-318. doi: 10.1080/10790268.2007.11753946.

[11] DeVivo MJ, Krause JS, Lammertse DP. Recent trends in mortality and causes of death among persons with spinal cord injury. Arch Phys Med Rehabil. 1999; 80: 1411-1419. doi: 10.1016/S0003-9993(99)90252-6.

[12] Lee S, Kim SH. A systematic review on the effects of respiratory rehabilitation programs in spinal cord injury. Korean J Rehabil Nurs. 2020; 23: 1-14. doi: 10.7587/kjrehn.2020.1. 
[13] Wang X, Zhang N, Xu Y. Effects of respiratory muscle training on pulmonary function in individuals with spinal cord injury: an updated meta-analysis. BioMed Res Int. 2020; 2020: 7530498. doi: 10.1155/2020/7530498.

[14] An SK, Shin WS. Effect of air stacking training on pulmonary function, respiratory strength and peak cough flow in persons with cervical spinal cord injury. Phys Ther Rehabil Sci. 2018; 7: 147-153. doi: 10.14474/ptrs.2018.7.4.147.

[15] Mueller G, Hopman MT, Perret C. Comparison of respiratory muscle training methods in individuals with motor and sensory complete tetraplegia: a randomized controlled trial. J Rehabil Med. 2013; 45: 248-253. doi: 10.2340/165019771097.

[16] Axen K, Pineda H, Shunfenthal I, Haas F. Diaphragmatic function following cervical cord injury: neurally mediated improvement. Arch Phys Med Rehabil. 1985; 66: 219-222. doi: 10.1016/0003-9993(85)90146-7.

[17] Oo T, Watt JW, Soni BM, Sett PK. Delayed diaphragm recovery in 12 patients after high cervical spinal cord injury. a retrospective review of the diaphragm status of 107 patients ventilated after acute spinal cord injury. Spinal Cord. 1999; 37: 117-122. doi: 10.1038/sj.sc.3100775.

[18] Frisbie JH, Brown R. Waist and neck enlargement after quadriplegia. J Am Paraplegia Soc. 1994; 17: 177-178. doi: 10.1080/01952307.1994.11735933.

[19] Haas F, Axen K, Pineda H, Gandino D, Haas A. Temporal pulmonary function changes in cervical cord injury. Arch Phys Med Rehabil. 1985; 66: 139-144.

[20] McMichan JC, Michel L, Westbrook PR. Pulmonary dysfunction following traumatic quadriplegia. recognition, prevention, and treatment. JAMA. 1980; 243: 528-531. doi: 10.1001/jama.243.6.528. 